\title{
MINI-UAV REMOTE CONTROL: A CASE STUDY AT POLITECNICO DI TORINO
}

\author{
S. Chiesa, S. Corpino, N. Viola, A. Cernusco, D. Gaglione, K. Pluciński
}

Politecnico di Torino, Department of Aeronautics and Space, C.so Einaudi 40, 10129 Torino, Italy. E-mails: sergio.chiesa@polito.it,sabrina.corpino@polito.it,nicole.viola@polito.it,acernusco@supereva.it, d.gaglione@teoresi.it,krzysztof.plucinski@polito.it Received 0110 2004, accepted 07102004
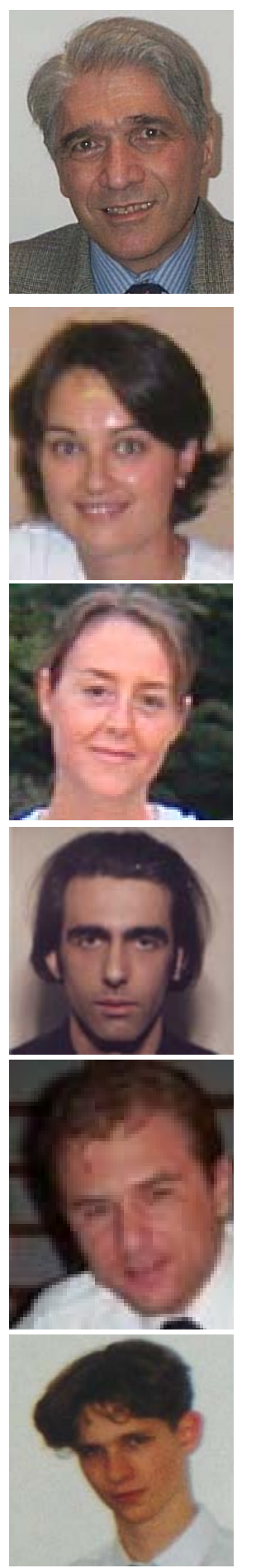

Sergio CHIESA got the degree in Aeronautical Engineering at Turin Polytechnic in 1972. For three years he had been employed in the field of Quality Assurance in an Italian firm involved in Tornado program. In 1976 he was enrolled at Turin Polytechnic as assistant of Aeronautical Design. Since 1978 he has been teaching Aeronautical Systems, with particular emphasis to Reliability and Logistic Support. Since 1990 has been full professor and in the 1991 was designed as chairman of Aerospace Engineering Department at Politecnico di Torino. He is author of many technical papers about aircraft systems, aircraft design and Reliability \& Logistic Support. He is member of SOLE (District 20, Chapter 02, Northern Italy) since 1981. From 1994 to 1997 he has been Chairman of SOLE Chapter 02. Member of AIDAA, he is the chairman of the Turin Section. He is the proponent and, since the foundation, the Chairman of the Diploma Course in aerospace engineering of the Turin Polytechnic. He is the chairman of the Council of "Area di Formazione" in Aerospace Engineering. He is editorial member of one scientific journal (Journal of Aerospace Engineering); he operates into the "systems engineering" research group of the Aerospace Engineering Department.

Sabrina CORPINO, Assistant professor

Work experience: Jul. 2003 - present: Assistant professor of Aerospace System Engineering at Politecnico di Torino.Nov. 1999 - present: Teaching at Politecnico di Torino as reader in CAD utilization and in on-board systems design and integration. Teaching at Alenia S.p.A. as trainer of new employees on aeronautical general subjects. Teaching at Alenia/AMMA post-Lau ream course as lecturer in new information technologies in aerospace design. Teaching at COREP-Politecnico di Torino MSc course as lecturer in new information technologies and RAMS techniques in aerospace design.

Education and training: 2003- Degree of $\mathrm{PhD}$ in Aerospace Engineering, 1999 - Degree in Aerospace Engineering - at Politecnico di Torino; 1992 - Maturità Scientifica at Liceo Scientifico Asproni, Cagliari, mark 60/60.

Publications: 17 scientific papers with co-authors.

Nicole VIOLA, PhD

Work experience: 2004 - present: Researcher in Aerospace System Engineering at Politecnico di Torino; 2000 present: Teaching at Politecnico di Torino as reader in simulation tool utilization and in aerospace systems design and integration; Teaching at Alenia S.p.A. as trainer of new employees on aeronautical general subjects; Teaching at Alenia/AMMA post-lauream course as lecturer in new information technologies in aerospace design.

Education and training: 1992 - Maturità Scientifica at Liceo Scientifico G.B. Bodoni, Saluzzo (CN), mark 54/60; 1999 - Degree in Aerospace Engineering at Politecnico di Torino, mark 105/110; 2004 - PhD in Aerospace Engineering at Politecnico di Torino.

Publications: 14 scientific papers with co-authors.

\section{Alberto CERNUSCO}

Education: 1991 - Technical Institute "Carlo Grassi; 2002- Politecnico di Torino, School of Aerospacial Engineering. Work experience: - Currently working on Entry Vehicle systems configuration with Alenia Spazio and Politecnico di Torino; - From September 2002 employed in the Politecnico di Torino in order to design a nano satellite in all its aspects. During this period of time I worked also on the UAV projects- May 2001 Stage at Flight Test Instrumentation of Alenia Aeronautica S.p.A. in Torino last 300 hours.

Davide GAGLIONE got the Degree in Aerospace Engineering in 2003 at Politecnico di Torino, Italy. In 2004 he took part to research projects dealing with the design of a min-UAV and of a nanosatellite. Both the mini-UAV and the nanosatellite are designed, manufactured and tested by ASSET (AeroSpace Systems Engineering Team) at Politecnico di Torino. Teoresi S.r.L now employs him. He is responsible for technical and educational activities of the national association PVI, which aims at the realization of low cost flight simulator.

Krzysztof PLUCIŃSKI, MSc

Education: 1998 - Stanisław Staszic High School in Warsaw; 2003 - Warsaw University of Technology; 2004 start of PhD, 3 - year course at Polytechnic of Turin.

Research interests: Aeronautical Engineering. 
Abstract. Recent development of modern micro and nano technologies allows aerospace vehicles extremely small size to be constructed. Wide availability and mass production of small dimension components drastically reduce the price of such vehicles. This fact allows them to be constructed by Universities and it makes them useful for education.

The Aerospace Systems Engineering Research Group (ASSET) at Politecnico di Torino the design, development and testing small, but quite complex, integrated systems. The goal of this paper is to present one of the contemporary works of this group: the Mini-UAV “ASSET” remote control/flight simulator site.

This paper contains a short presentation of the Mini-UAV, a description of its onboard and ground systems and the use of COTS components. The paper explains how the ground control site has also been designed to run as a flight simulator. For this purpose MICROSOFT FLIGHT SIMULATOR for 3D scenario visualization and Matlab/Simulink for airplane and environmental modeling has been used and integrated. In the system are included possibilities of ALTIA Design software exploitation for avionic display visualization. In particular some new modes for HUD, conceived and simulated, are presented and discussed in the paper.

The hardware configuration of the Remote Control System/Flight Simulator is briefly described.

Keywords: mini-UAV, remote control, COTS components, micro-electro-mechanical systems, flight simulator, HUD.

\section{Introduction}

In recent years, thanks to the rapid development of information technology, a huge amount of technical progress has occurred. This fact has lead to two main consequences: on one hand it has made the miniaturization of hardware feasible, and on the other hand it has allowed the decrease of the cost of electronic components.

The development of mass-production has increased the availability of small-sized electromechanical components, so called Micro-Electro-Mechanical Systems (MEMS), that can be easily bought in shops. This fact has allowed engineers to design and manufacture the onboard systems of vehicles from already existing components, which are usually called Commercial Off-The-Shelf components (COTS).

COTS components, characterized by reduced dimensions, small weight, and low cost, can be used to build quite complex and effective Guidance Navigation and Control (GN\&C) systems, necessary for small aerial platforms. At the same time, these platforms are useful flying test-beds to validate MEMS technology systems.

These systems, after being subjected to proper validation, can be integrated in flying test-beds such as small aerospace vehicles.

Universities and countries with limited budgets for aerospace research can focus on these cost-effective flying test-beds, which are surely useful to gather information even though they are simple, small, and thus affordable. Such low cost aerospace platforms also appear quite appealing from an educational point of view since their design, development, and testing can be easily dealt with during both undergraduate and graduate courses.

These concepts are summed up in Figure 1.

In order to investigate this interesting field of research, at Politecnico di Torino, under the coordination of professor Sergio Chiesa, the AeroSpace System Engineering Team (ASSET) has been constituted.

The aim of the group is the design, development, and testing of extremely small-sized integrated aerospace systems. ASSET has been involved for a few years now into quite a lot of research activities dealing with this subject matter.

Besides the aforementioned activities, others should be noted:
- the design, manufacture, and testing of a remotely controlled terrestrial vehicle, called Mini-Rover, (Figure 2) [1];

- the design, manufacture, and testing of a nanosatellite, named PicPot (Figure 3);

- the design, manufacture, and testing of a remotely controlled flying vehicle: the Mini-UAV "ASSET" (Fig 4).

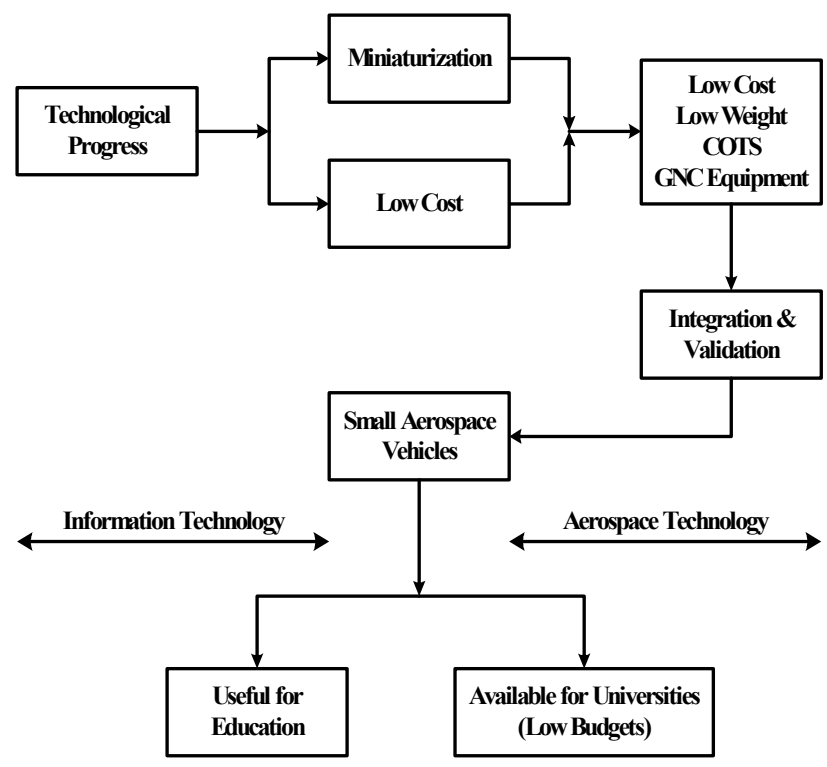

Fig 1. General considerations' flow-chart

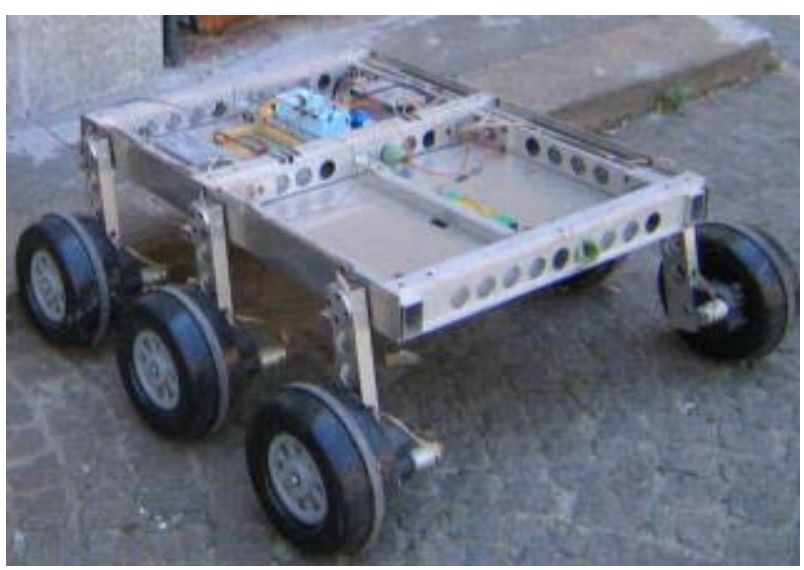

Fig 2. Mini-Rover 
Future developments of the present research activities are:

- investigating innovative configurations of flying testbed;

- consideration of a fleet of mini terrestrial and/or aerial platforms of a fleet, useful to study the control strategies, which could then be developed to be suitable for fleet's control of such platforms.

Please note that ASSET is involved in these topics from the points of view of both research and education.

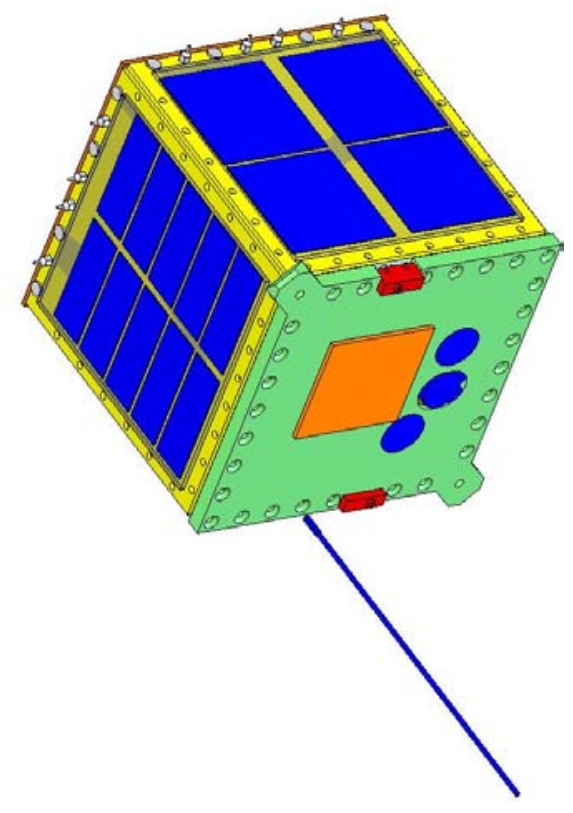

Fig3. Nanosatellite PicPot

\section{Mini-UAV description}

The Mini-UAV "ASSET" is a radio controlled flying test-bed for MEMS systems. The chosen configuration is tailless with one electrically driven pusher propeller and a micro camera in the nose. The Mini-UAV already flies (Figure 4).

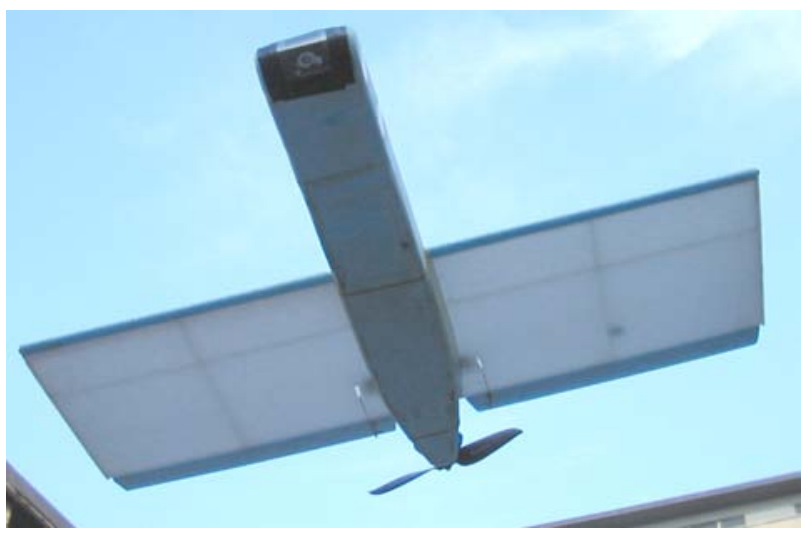

Fig 4. Mini-UAV in flight

\subsection{Technical data}

The tables below show ASSET Mini-UAV's main technical data (Tables 1, 2, 3 and 4).

Table 1. Dimensions of Mini-UAV's

\begin{tabular}{|l|l|}
\hline \multicolumn{2}{|l|}{ Dimensions } \\
\hline Total Length & $0.614 \mathrm{~m}$ \\
\hline Wingspan & $0.8 \mathrm{~m}$ \\
\hline Wing area & $0.232 \mathrm{~m}^{2}$ \\
\hline Wing chord & constant $0.29 \mathrm{~m}$ \\
\hline Profile & Eppler E221 \\
\hline
\end{tabular}

Table 2. Weights of Mini-UAV's

\begin{tabular}{|l|l|}
\hline \multicolumn{2}{|l|}{ Weights } \\
\hline Maximum TO weight & $0.56 \mathrm{~kg}$ \\
\hline Empty weight & $0.36 \mathrm{~kg}$ \\
\hline
\end{tabular}

Table 3. Performance of Mini-UAV's

\begin{tabular}{|l|l|}
\hline Performance \\
\hline Maximum speed & $55 \mathrm{~km} / \mathrm{hr}$ \\
\hline Operation range & $500 \mathrm{~m}$ \\
\hline Endurance & about $25 \mathrm{~min}$ \\
\hline
\end{tabular}

Table 4. Manufacture of Mini-UAV's

\begin{tabular}{|l|l|}
\hline \multicolumn{2}{|l|}{ Manufacturing } \\
\hline Wings & $\begin{array}{l}\text { Made of 3 } \mathrm{mm} \text { sheets of Depron. } \\
\text { Ailerons, one per wing works also as } \\
\text { elevators }\end{array}$ \\
\hline Fuselage & Made of $6 \mathrm{~mm}$ sheets of polistyren. \\
\hline
\end{tabular}

\subsection{On board systems of Mini-UAV}

Mini-UAV's on-board systems are listed below:

- propulsion system;

- flight control system;

- navigation and communication system;

- power supply system;

- communication system;

- payload.

To keep the cost down and to investigate their applicability, COTS components have been widely used. The tables below show some technical data of the main on-board components:

- Propulsion system

\begin{tabular}{|l|l|}
\hline \multicolumn{2}{|l|}{ Minimotor HACKER B20 31S Brushless } \\
\hline Diameter & $20 \mathrm{~mm}$ \\
\hline Length & $42.5 \mathrm{~mm}$ \\
\hline Mass & $39.69 \mathrm{~g}$ \\
\hline Gearbox & $4: 1 \mathrm{planetary}$ \\
\hline Propeller Graupner $0.227 \mathrm{x} 0,152 \mathrm{~m}$ \\
\hline \multicolumn{2}{|l}{} \\
\end{tabular}


- Flight control system

\begin{tabular}{|l|l|}
\hline Radio control GRAUPNER MC24 receiver \\
\hline Servomechanism GRAUPNER C1081 \\
\hline \\
\\
\hline Dimensions & $23 \mathrm{x} 10 \mathrm{x} 20 \mathrm{~mm}$ \\
\hline Mass & $6.2 \mathrm{~g}$ \\
\hline Torque & $1.08 \mathrm{Nm}$ \\
\hline Alimentation & $4,8 \mathrm{~V}$ \\
\hline
\end{tabular}

- Navigation and communication system: Micro GPS RGM3000/REB3000 series

\begin{tabular}{|l|l|}
\hline \multicolumn{2}{|l|}{ Micro GPS RGM3000/REB3000 series } \\
\hline Dimensions & $21,5 \times 28,5 \mathrm{~mm}$ \\
\hline Data update time & $1 \mathrm{~s}$ \\
\hline $\begin{array}{l}\text { Position determination } \\
\text { accuracy }\end{array}$ & $25 \mathrm{~m}$ \\
\hline Alimentation & $3,3 \mathrm{~V}$ \\
\hline Protocol & $\mathrm{NMEA}$ v. 2.2 \\
\hline GPS Data-Link ConnexRFAC4424-200 $2,4 \mathrm{GHz}$ \\
\hline \multicolumn{2}{|l|}{} \\
\end{tabular}

- power supply system:

\begin{tabular}{|l|l|}
\hline Battery Kock $1200 \mathrm{mAh}$ (lithium polymers) \\
\hline & \\
\hline Capacity & $1200 \mathrm{mAh}$ \\
\hline
\end{tabular}

- Payload

\begin{tabular}{|l|l|}
\hline Minicamera Ominvision $1 / 3$ ' CMOS \\
\hline
\end{tabular}

\begin{tabular}{|l|l|}
\hline Standard & PAL \\
\hline Alimentation & $5 \mathrm{~V}( \pm 10 \%) \mathrm{dc}$ \\
\hline \multicolumn{2}{|l|}{ Possibility of downward camera rotation $60 \mathrm{deg}$} \\
\hline Video transmission system F-type antenna \\
\hline \multicolumn{1}{|l}{} \\
\multicolumn{1}{|l|}{} \\
\hline Dimensions & $28 \times 24 \times 8 \mathrm{~mm}$ \\
\hline Mass & $10 \mathrm{~g}$ \\
\hline Frequency & $900-1200 \mathrm{MHz}$ \\
\hline Alimentation & $7,5-12 \mathrm{~V} \mathrm{dc}$ \\
\hline
\end{tabular}

Figure 5 illustrates the Mini-UAV's 3D CAD model and the layout of the on-board system [2].

\section{Configuration of Remote control system}

Terrestrial and aerial vehicles integrated with GN\&C components, based on MEMS technology, represent autonomous systems that can be remote controlled. An interesting topic is to design, test, and develop the Remote Control System (RCS). The aim of this topic is to create an operator friendly control base for UAV, equipped with all necessary control tools and instruments.

Following step-by-step development, at first the numerical model of the Mini-UAV was created. This task has been accomplished in a Matlab/Simulink environment. In order to complete the model, two Simulink libraries, Aerospace Blockset and AeroSim Blockset, were used. Figure 6 shows the top view of the Mini-UAV's Simulink model.

After being used as design tool, the availability of the model suggested the implementation of a Mini-UAV Flight Simulator, which could be based on the same hardware of the Remote Control System (RCS). Thus a dual function for the system was developed [3].

\subsection{Software used}

For the purpose of simulation and control software listed below was used:

- Matlab/Simulink, the most widely used software for dynamics systems simulation;

- Altia Design, software designated for creation, management, and modification of graphic interfaces. Altia Design contains programs for graphic design and $\mathrm{C}$ code applications generation;

- Microsoft Flight Simulator, the most popular commercial software for flight simulation;

- Microsoft Visual $\mathrm{C} / \mathrm{C}++$ computer language.

\subsection{Real time problem}

Simulator, the simulation must be real time, but the software used for modeling works in Microsoft Windows, which is not a real time environment. 


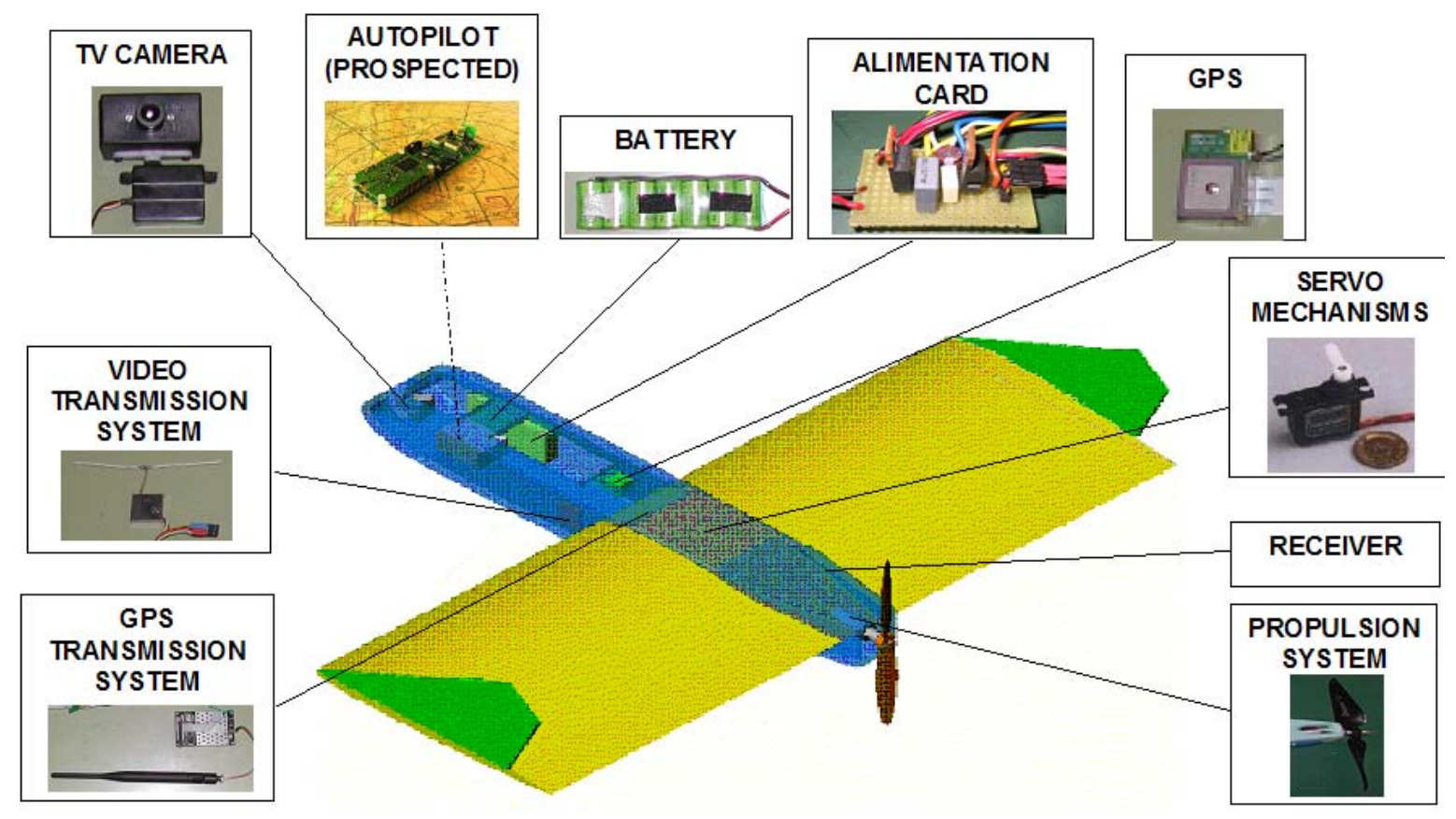

Fig 5. Layout of on-board systems of Mini-UAV

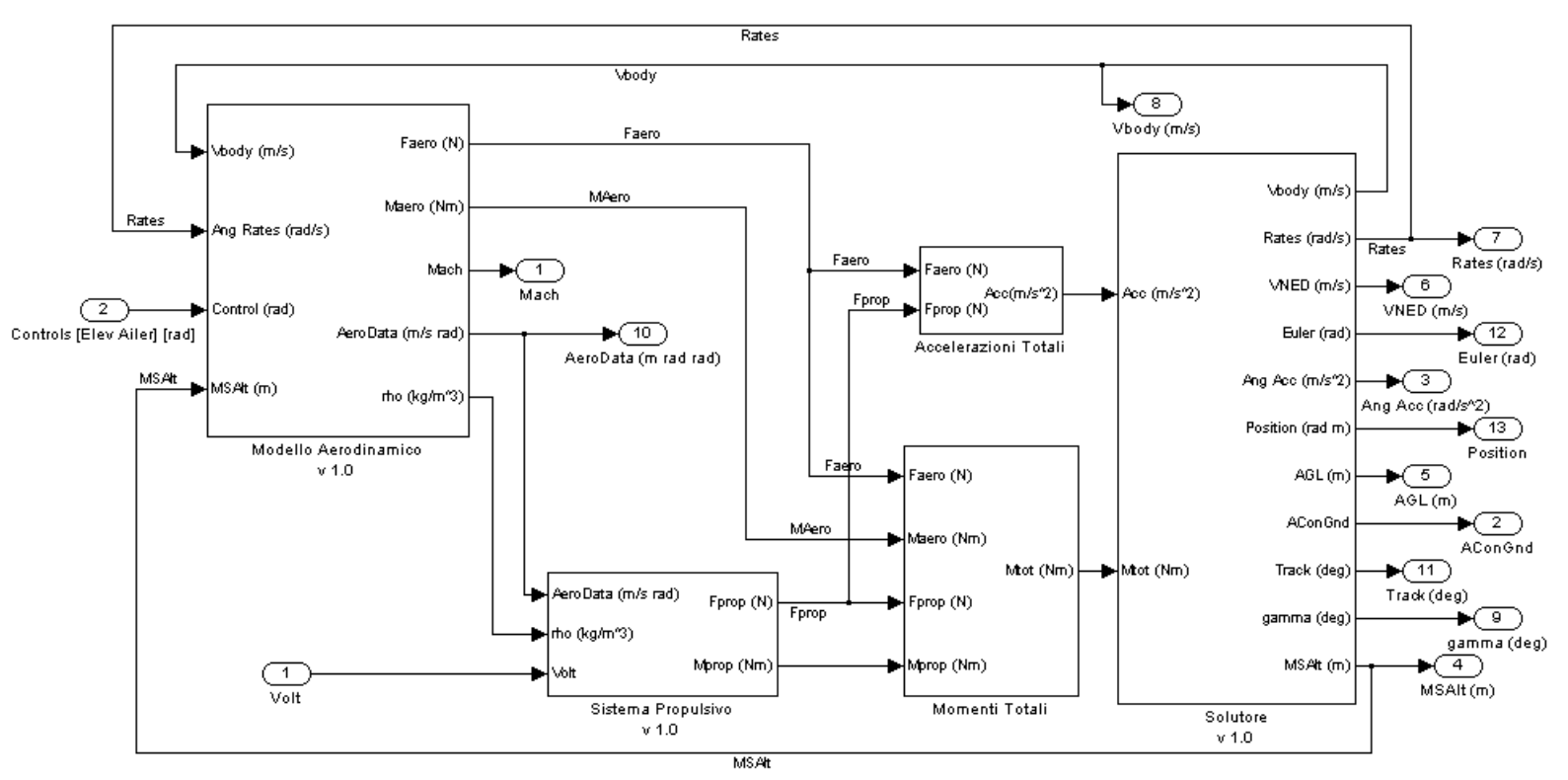

Fig 6. Mini-UAV Simulink model

MathWorks Inc. gives us the solution of this problem: in fact it offers different tools to deal with the real time problem. The basic Simulink toolboxes that allow one to cope with the real time problem are Real Time Workshop (that, for modeling and RCS generation, is used for source code creation and compilation), Real Time Windows Target, and XPC Target.

In order to make the simulation model run in real time, XPC Target has been chosen. It assumes the use of two PCs, connected by a serial port or local network, working as:

- Host PC (Main PC): containing general environment as Windows and Matlab/Simulink;
- XPC Target PC (Target PC): containing real time applications that are in communication with Simulink.

Utilization of XPC Target allows us to generate a Matlab file that can be loaded on boot floppy disc. This boot file, loaded on the PC Target, substitutes for the already existing operational system, thus creating a real time environment.

\subsection{Configuration of system for RCS integrated with computerized model of Mini- UAV}

As was said, Microsoft Flight Simulator (MSFS) has been chosen for the visualization of the flight scenario. 
This advanced three-dimensional graphic application requires a computer of good performance. In order not to make MSFS work on the Main and Target PC, a third PC, called Visual PC, has been added to the two existing computers. The Visual PC works in a MS Windows environment and is used for three dimensional flight representations. All three computers are connected in local network.

Applications and interfaces created under Altia Design have also been installed On the Main PC and Visual PC. Thanks to this software, it has been possible to obtain an interactive flight map (on the Main PC) and a visualization of the flight instruments (on the Visual PC) (Figure 7). In particular, a display like HUD can be superimposed on the MSFS scenario.

As has already been mentioned, the Main PC works in an MS Windows environment and contains the MiniUAV's computerized model, built in Matlab/Simulink. This model is then executed in a real time environment on the Target PC, and its output data are send back to the Main PC (Figure 7).

\subsection{Configuration of system's for RCS integrated with real Mini-UAV}

A very important task is the integration of the RCS with the real Mini-UAV.

The fundamental issue to be solved is the communication between the RCS and the real airplane.

It is necessary to distinguish between two types of communication:

1. Orders are sent from the ground station to the MiniUAV to control it;

2. Telemetry (i.e. data from airplane, including flight conditions, navigation and other data from the onboard systems) and images, taken from the videocamera, are downlinked from the Mini-UAV to the ground.

The first type of communication can be acquired both by an on-board receiver system and by another onground receiver. Such an on-ground receiver is connected to the Main PC, which performs the functions of acquiring, translating, and registering the signals generated by the pilot via the radio control transmitter (Figure 8).

The second type of communication consists of telemetry data and video images. The latter are acquired by on-ground systems and may be sent to the Main or to the Visual PC. Afterwards they can be displayed on one connected monitor. Telemetry data are acquired by onground receiver systems and sent to the Target $\mathrm{PC}$ where can be used to calculate the airplane position in a synthetic environment. In this case, the Mini-UAV operator controls the airplane by using the results of calculations, which can be displayed both as a flight map generated by Altia Design software and as a flight visualization in MSFS, which runs on the Visual PC (Figure 8). The monitor connected to the Visual PC may display either the MSFS scenario or the video, which is generated by the images transmitted from the TV camera, placed on-board the Mini-UAV. Please note that these two different kinds of scenario, the simulated one, obtained via MSFS, and the real one, taken from the TV camera, cannot be used at the same time. In both cases, flight instruments created in Altia Design can be added as a Heads Up Display (HUD) to the synthetic environment or to the real scenario.

This solution allows one to control the airplane by means of a virtual environment only, that is to say independently from the work and position of the camera (the camera has the possibility of being rotated 60 degrees downward). This solution can be useful in case of bad weather, or at night.

The configuration of the configuration of the hypothetical system in case of the integration of the RCS with a real Mini-UAV, and the interaction between the Mini-UAV and the ground station are shown in Figure 8.

\subsection{Requirements for software and hardware}

\subsubsection{Main PC} below:

The software requirements for he Main PC are listed

- Operation system Windows NT/2000/XP;

- Matlab and Simulink with toolboxes: Aerospace Blockset, AeroSim Blockset, Real Time Workshop, XPC Target;

- Altia Design 5.1;

- Microsoft Visual $\mathrm{C} / \mathrm{C}++$.

As far as the hardware is concerned, we can say that a high performance computer is not a necessity. Any standard modern PC with medium characteristics is enough. The number of calculations being performed on this computer is not huge compared to the other two PCs, because the airplane's numerical model is being solved on Target PC. Altia Design doesn't require many resources. Microsoft Visual $\mathrm{C} / \mathrm{C}++$ is only used to create interfaces and works independently. A network card is however necessary.

A "packet" Wide FS (Ms Flight simulation module) must also be installed on Main PC to enable communication between the Main PC and Ms Flight Simulator installed on the Visual PC. 


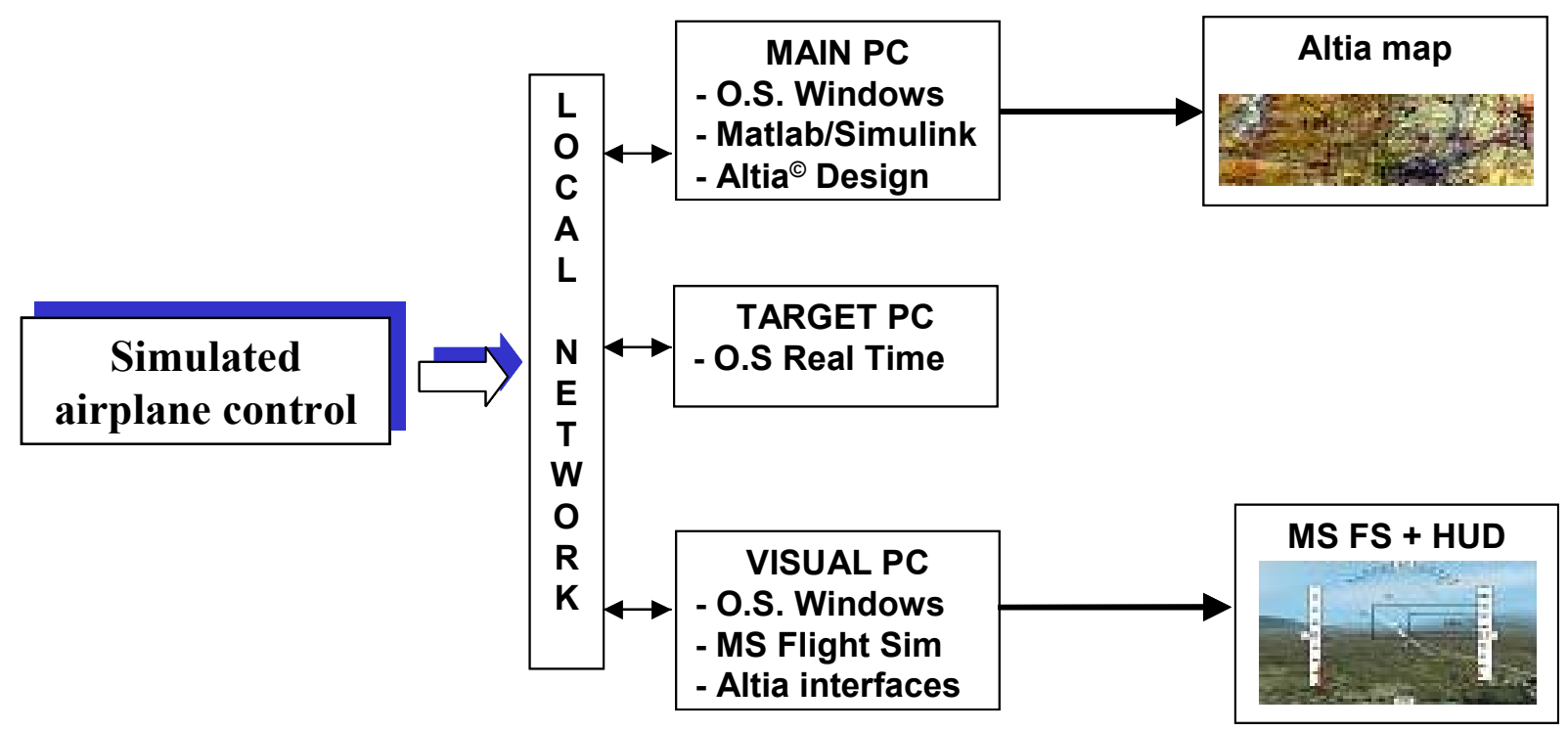

Fig 7. Configuration of the system for RCS integrated with Mini-UAV numerical model

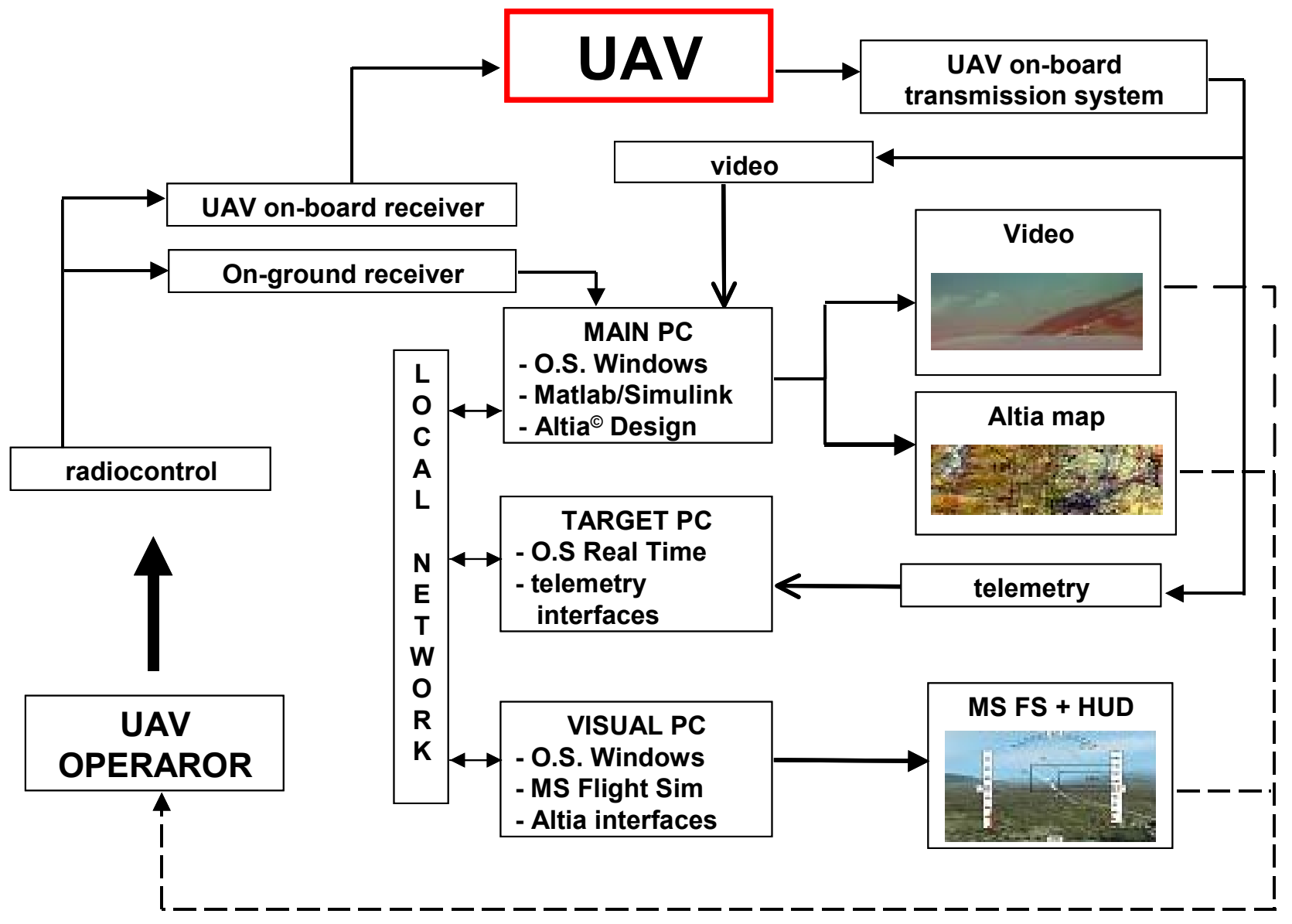

Fig 8. Prospective hypothetical system configuration integrated with real mini-UAV

\subsubsection{Target $P C$}

No software preinstalled on the hard disc is required. If any software is installed, it does not matter what kind it is. The Target PC starts from a boot floppy disk and loads an operation system crated before in Matlab. The aim of this system is the execution of the Simulink model from the Main PC, being performed in real time. During installation of the real time operation system, it creates "space" in RAM memory, in which the application is loaded. During this process and during application work, no data is deleted or saved on the hard disk.

As far as the hardware is concerned, any standard modern PC with medium characteristics is enough in fact only the execution of the airplane model is required. A network card compatible with XPC Target is necessary. 


\subsubsection{Visual PC} below:

Software requirements for the Visual PC are listed

- Microsoft Flight Simulator with module Wide FS (to allow communication with Main PC);

- Applications and interfaces generated under Altia Design.

As far as the hardware is concerned, the Altia applications do not require a high performance computer. A high performance computer is necessary to host Ms Flight Simulator because of its advanced graphics.

Here are some proposed computer data for the Visual PC:

- Windows 98/Me - $64 \mathrm{MB}$ Ram;

- Windows 2000/XP - 128 MB Ram;

- Processor: $450 \mathrm{MHz}$;

- Free disc space: 1,8 GB;

- Graphic Card: $8 \mathrm{MB} / 3 \mathrm{D}$ with driver direct 7.0 or higher;

- Installed driver DirectX9 or higher.

\subsection{Altia Design solutions}

For the purpose of simulation and control base's development, the Altia Design software has been used to create two different graphic interfaces:

1. The Heads-Up Display, the most significant characteristic of which is that the pilot can see a lot of information at the same time on one single monitor. Figure 9 illustrates an example of the HUD created in the Altia Design environment;

2. The Interactive Navigation Map, which is constituted of the Altia interactive map and the airplane's schematic representation. They work together, making it possible to track the airplane while it is flying. Figure 10 shows an example of the Interactive Navigation Map.

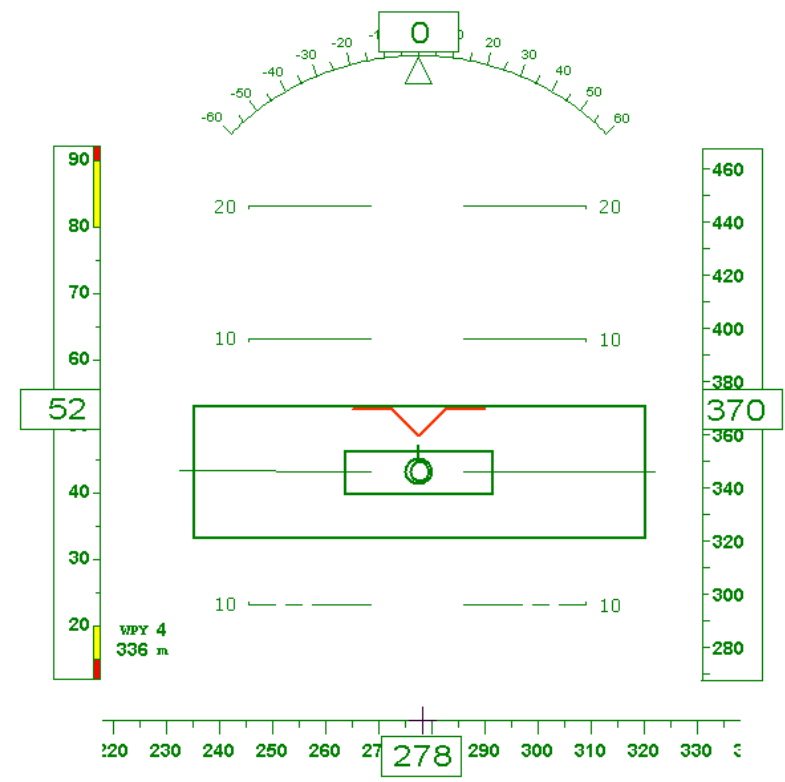

Fig 9. Head-Up Display created in Altia Design environment

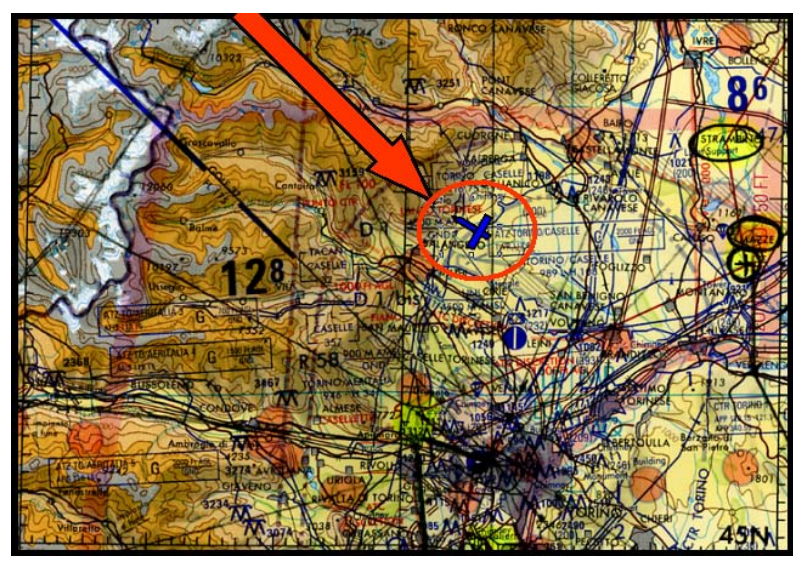

Fig 10. Interactive Navigation Map created in Altia Design environment

\subsection{Results and future development}

As was said in paragraph 3.3, a real time flight simulation of the Mini-UAV has been obtained.

The simulation requires two different monitors:

1. One displaying the Interactive Navigation Map, which is a bi-dimensional visualization;

2. The other displaying the three-dimensional flight representation built in a Microsoft Flight Simulation environment. The HUD, created by means of Altia Design software, is placed on the three-dimensional visualization to get the final result shown in Figure 11 .

The solution presented on the second screen can be considered the classic visualization of the HUD.

A different idea has been conceived thanks to the possibilities offered by MS Flight Simulator and its easy integration with the outputs of Altia Design software.

Unlike the usual view of the HUD, which implies that the pilot is seated inside the vehicle, the new idea for the Remote Control System is to display an external view of the airplane, as if the pilot or, better, the remote pilot could actually see the vehicle from behind it. Different angles of view and distances could obviously be considered. An example of the external three-dimensional view of the flying vehicle is illustrated in Figure 12.

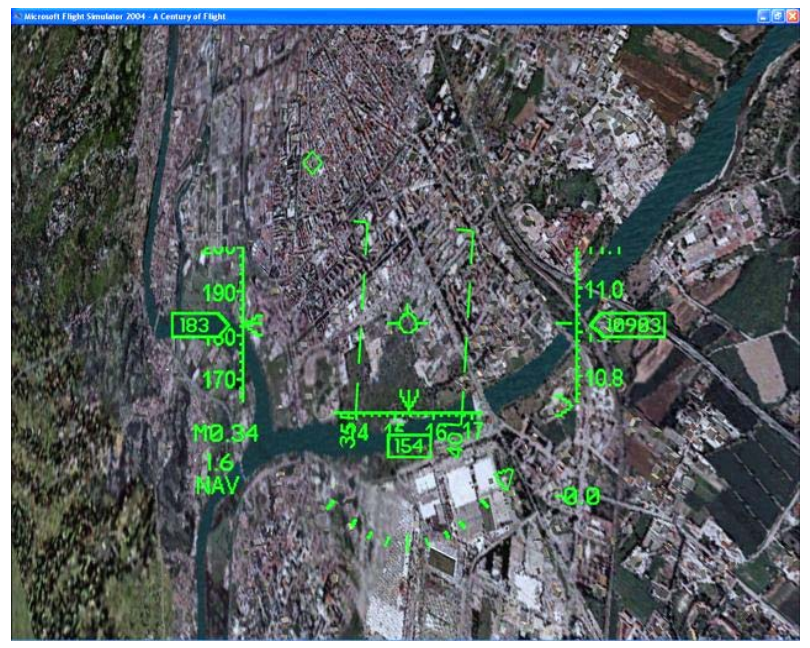

Fig 11. Example of HUD placed on 3D flight visualization 


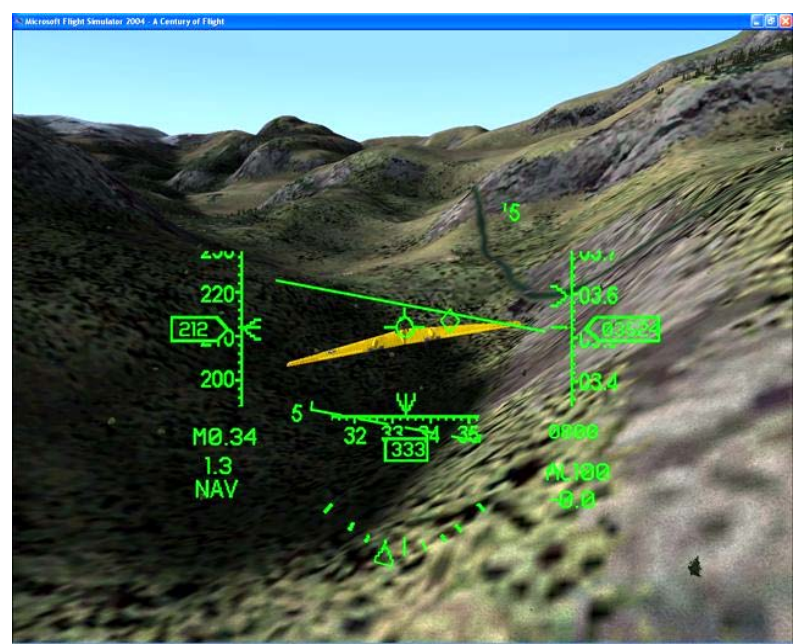

Fig 12. Example of external 3D view of a flying vehicle

An advantage of this unusual three-dimensional view of the airplane consists of the possibility of tracking the airplane while staying some meters behind it. In some situations for UAV operators, this kind of flight representation may be more convenient then being inside the cockpit.

It is obvious that both kinds of like the HUD displays can be used to control the real airplane when superimposed either on the video taken from the TV camera or on the simulated environment obtained by means of MSFS.

Future plans include:

- upgrading the mathematical model;

- developing the integration between the Interactive Navigation Map and the flight indicators (for example, the creation of classical instruments);

- creating a proper Mini-UAV graphical representation to be used in the external HUD 3D view.

\section{Remote Control System (RCS)}

The RCS/Flight Simulator is shown in Figure 13.

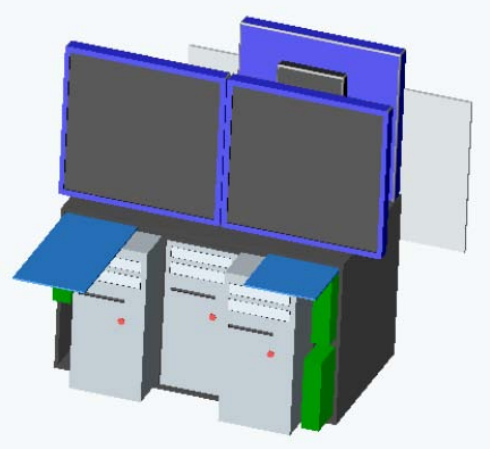

Fig 13. RCS/Flight Simulator

We can see a solution with three PCs and three videos, two for the pilot (usually one for visualization of the external scenario, directly from a TV camera or simulated from MSFS and the other for the representation of instruments by Altia Design) and one, placed opposite to them, for the instructor.

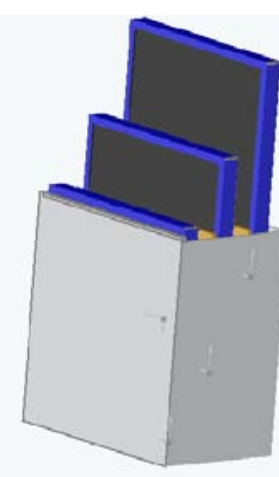

Fig 14. Transportability study

This configuration for RCS been studied taking into account the aspect of transportability, as shown in figure 14. A further improvement for transportability, now still under study, foresees one PC and one video (the one for the instructor) being substituted by one laptop.

\section{Conclusions}

Today the RCS allows us to control the ASSET Mini-UAV by means of radio control systems both when it is in the range of sight and when it is out of it thanks to GPS and TV camera data. Another chance offered at present by the RCS/Flight Simulator is the possibility of performing simulated flights by means of the Mini-UAV simulation model with a coordinated, realistic external scenario given by Microsoft Flight Simulator. In case it is used as RCS, with the airplane in the loop, the simulation model does not work, except of some software functions suitable to interface telemetry with Altia Design and MSFS. While the former gives us in a continuous mode the representation of the flight instruments, the latter, which is fundamental in the simulative mode, can be used alternative to a TV camera, for example at night or in bad weather conditions.

In the near future, a COTS autopilot, which has already been selected and is shown in figure 15, will be installed on board the ASSET Mini-UAV, thus making it capable of performing autonomous flight. The autopilot will then be modeled and to be added to the Simulink numerical model of the vehicle for flight simulation purposes.

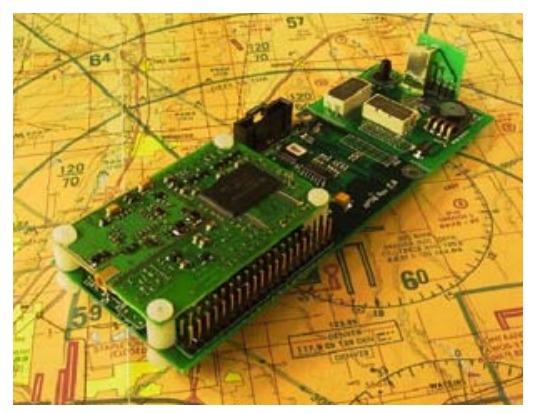

Fig 15. Autopilot UAV Flight AP 50 


\section{Acknowledgements}

The authors thank Teoresi S.r.l. Corporation of Torino, dealer of Design ALTIA software, for its close cooperation in developing this work.

\section{References}

1. Corpino S., Pasquino M., Perassi A. et al. Advanced system concept driven by supportability target // ESREL Congress, Turin, Sept. 2001. - Turin, 2001.
2. Gaglione D. Sistemi di guida, navigazione e controllo, a basso costo per piccole piattaforme aerospaziali // Tesi di Laurea, Politecnico di Torino, July 2003. - Turin, 2003.

3. Frezet A. Posto di controllo per il pilotaggio remoto e la simulazione del volo di mini-UAV // Tesi di Laurea, Politecnico di Torino, July 2004. - Turin, 2004. 